\title{
EL ARBITRAJE ELECTRÓNICO COMO MEDIO DE RESOLUCIÓN DE CONTROVERSIAS TURÍSTICAS
}

\section{ELECTRONIC ARBITRATION AS A MEANS OF RESOLUTION OF TOURIST CONTROVERSIES}

\author{
JUAN FRANCISCO RODRÍGUEZ AYUSO ${ }^{1}$
}

\begin{abstract}
Doctor internacional en Derecho digital por la Universidad de Bolonia (Italia)
Profesor universitario de Derecho Digital y de Protección de Datos

Universidad Internacional de La Rioja (Logroño)

Consultor legal de Ciberseguridad, Compliance y Protección de Datos
\end{abstract}

\begin{abstract}
Resumen
El presente trabajo ofrece unas consideraciones generales acerca de la utilización de las modernas tecnologías de la información y la comunicación en los procedimientos extrajudiciales de resolución de controversias que se desarrollan en el ámbito del e-commerce. Para ello, se procede a un análisis de los principales rasgos distintivos de estos métodos alternativos, con especial incidencia en los sistemas de arbitraje ODR y en su posible aplicabilidad para dirimir disputas nacidas en el seno del sector turístico.
\end{abstract}

Palabras Clave: comercio electrónico, contratación electrónica, ADR, ODR, arbitraje, sector turístico.

\begin{abstract}
This paper provides some general considerations about the use of modern information and communication technology in the alternative dispute resolution procedures that developed in the field of e-commerce. To do this, we proceed to an analysis of the main distinguishing features of these methods, with special emphasis on ODR arbitration systems and its potential applicability to settle disputes arising within the tourism sector.
\end{abstract}

Key Words : e-commerce, e-procurement, ADR, ODR, arbitration, tourism.

Fecha de recepción: 26 de julio de 2018 Fecha de aprobación: 5 de diciembre de 2018

${ }^{1}$ juanfrancisco.rodriguez@unir.net 


\section{NUEVAS TECNOLOGÍAS DE LA INFORMACIÓN Y DE LA COMUNICACIÓN: EL OCASO DE LA DISTANCIA Y EL TIEMPO}

Resulta un hecho incuestionable que el surgimiento y posterior desarrollo de las nuevas tecnologías de la información y la comunicación (TIC's) ha posibilitado la transformación de la configuración de la sociedad hacia nuevas formas hasta hace poco tiempo desconocidas e inimaginables. De manera progresiva e imparable, este radical avance está favoreciendo un modelo de vida caracterizado en esencia por el incesante crecimiento de la comunicación a distancia y la extraordinaria rapidez en la transmisión de la información, protagonista fundamental de esta nueva etapa que se abre espacio. Tiene lugar, de este modo, el tránsito de la vetusta sociedad industrial o postindustrial a la incipiente sociedad de la información ${ }^{2}$.

Las principales ventajas que trae consigo este fenómeno parecen, en la actualidad, evidentes: gracias a él, ciudadanos de todo el mundo pueden acceder desde cualquier punto o terminal y en cualquier momento a información y documentación, actual o pretérita, sita a miles de kilómetros, desde su asiento y sin necesidad de desplazarse, con el consiguiente ahorro, temporal y económico, que ello supone ${ }^{3}$. Del mismo modo acaece una apertura extraordinaria de las posibilidades de comunicación con otras personas a escala internacional, sin limitación cuantitativa de ningún tipo, sectorial o espacial. Y todo esto acompañado del nacimiento de novedosas y originales oportunidades de entretenimiento surgidas al albor de esta nueva cultura cibernética ${ }^{4}$.

Desde una perspectiva puramente mercantil, la aplicación de estas modernas tecnologías a la actividad económica, más específicamente a aquella que tiene lugar en forma de intermediación entre la producción, de un lado, y el consumo, de otro, origina el nacimiento de una nueva modalidad de comercio, distinto y alternativo (que no incompatible) del comercio tradicional y que ha dado en conocerse como comercio electrónico ${ }^{5}$. Los

2 CARRASCOSA LÓPEZ, V./RODRÍGUEZ DE CASTRO, E. P./POZO ARRANZ, M. A., $L a$ contratación informática: el nuevo horizonte contractual. Los contratos electrónicos e informáticos, Granada, Ed. Comares, 2012, pp. 435-436.

${ }^{3}$ Conviene precisar, no obstante, el distinto nivel de acceso que a este desarrollo tecnológico se produce entre regiones económicamente más y menos favorecidas, originando una importante discriminación de partida. Así es, la distinta participación en este nuevo modelo no hace sino acrecentar, en principio, las desigualdades entre inforricos (con posibilidades de conexión) e infopobres (en situación de desconexión), que hace a algunos autores hablar, incluso, de "apartheid digital" [AMAR RODRÍGUEZ, V. M., «La interculturalidad tecnológica: inforricos e infopobres», en Inmigración, interculturalidad y convivencia, 2002, p. 369, y «Tecnología y educación: el resurgir del cuarto mundo» en Historia Actual Online, núm. 8, 2015, p. 180; CABREROALMENARA, J./AMAR RODRÍGUEZ, V. M./MONTANER, J., «Tecnologías de la información y la comunicación: más de lo mismo o más y diferente en educación», en Tavira: Revista de ciencias de la educación, núm. 24, 2016, p. 132; RUBÉN BLANCO, J., «Sobre sujetos virtuales y mundos digitales: el caso de las comunidades virtuales», en Política y sociedad, núm. 30, 1999, p. 203; PÉREZ LUÑO, A. E., «Internet y Derecho», en AA.VV., Informática y Derecho, Jornadas celebradas en Mérida, 2014, p. 727].

4 MIRANDA SERRANO, L. M./ VELA TORRES, P. J./PRÍES PICARDO, A., La contratación mercantil. Disposiciones generales. Protección de los consumidores, Madrid, Ed. Marcial Pons, 2016, p. 336; SUBIRANA, B./VALOR, J./CARVAJAL, P., «Entender Internet: una teoría sobre la evolución de los mercados electrónicos vía Internet», en Revista de Antiguos Alumnos del IEEM, núm. 3, 2010, p. 87.

${ }^{5}$ MIRANDA SERRANO, L. M./ VELA TORRES, P. J./PRÍES PICARDO, A., La contratación... cit., p. 336. 
beneficios que se anudan a estos cambios no son tampoco desdeñables, ni por extensión ni por intensidad. Para el consumidor o usuario ${ }^{6}$, la implementación de este desarrollo telemático permite el acceso a un mayor número de bienes y servicios. Ello, unido a la reducción para los productores de aquellos costes derivados de la eliminación de intermediarios ${ }^{7}$ y la sustitución de una infraestructura física por una de carácter virtual sin necesidad de almacenamiento material, permite al comprador la obtención de mejores (más baratos) precios, un mayor y más fácil acceso a información acerca de las características de los bienes y servicios ofertados, una mejora en la calidad de los mismos, una mayor personalización (las ofertas se encuentran más ajustadas a las necesidades de los clientes), un sustancial incremento del poder negociador merced a la creación de las comunidades virtuales ${ }^{8}$ y una minoración del tiempo empleado para efectuar la adquisición al facilitarse la comparación simultánea de precios, condiciones y características ${ }^{9}$. Para el vendedor o empresario, este traslado del escenario de venta de la calle al ordenador ${ }^{10}$ permite la obtención de información acerca de los competidores gracias al aprendizaje organizativo, así como una mayúscula apertura de las oportunidades de negocio, toda vez que los potenciales clientes a los que ahora puede acceder se multiplican de manera extraordinaria, posibilitando, asimismo, una mayor celeridad en el

${ }^{6}$ En torno a las nociones de consumidor, usuario, empresario y profesional, véase BOTANA GARCÍA, G., Comercio...cit., pp. 208 y ss.; BARRAL VIÑALS, I., «La mediación y el arbitraje de consumo: explorando sistemas de ODR», en IDP: revista de Internet, Derecho y Política, núm. 11, 2010, p. 5. Todo ello, no obstante, sobre la base de las modificaciones experimentadas en los artículos 3 y 4 del Real Decreto Legislativo 1/2007, de 16 de noviembre, por el que se aprueba el texto refundido de la Ley General para la Defensa de los Consumidores y Usuarios y otras leyes complementarias por parte de la Ley 3/2014, de 27 de marzo, por la que se modifica el texto refundido de la Ley General para la Defensa de los Consumidores y Usuarios y otras leyes complementarias, aprobado por el Real Decreto Legislativo 1/2007, de 16 de noviembre.

${ }^{7}$ Con la aparición de Internet, la importancia de los intermediarios (mayoristas y minoristas) se reduce, ya que se facilita y favorece el contacto entre productores y consumidores. De igual modo, cualquiera de los intermediarios puede relacionarse con el consumidor final, lo que contribuye a hacer innecesarios el resto de eslabones de la cadena tradicional. Cierto es, no obstante, que con la aparición y expansión del comercio electrónico también aparecen nuevos intermediarios hasta ahora desconocidos [BOTANA GARCÍA, G. A., Comercio electrónico y protección de los consumidores, Las Rozas (Madrid), Ed. La Ley, 2011, pp. 92-93, 104].

8 Aplicado a este campo, las comunidades virtuales hacen referencia a aquellos grupos de personas dotados de cierta estabilidad que se hallan conectados entre sí en línea y someten a discusión uno o varios aspectos cuyo interés es compartido por todos ellos, pudiendo ejercer presión conjunta a fin de alcanzar un objetivo común en materia comercial [FLAVIÁN BLANCO, C./GUINALÍU BLASCO, M., «La comunidad virtual: factor clave del éxito de algunos negocios en Internet», en Boletín Económico del ICE, núm. 2794, 2004, p. 24; RUBÉN BLANCO, J., «Sobre sujetos virtuales y mundos digitales: el caso de las comunidades virtuales», en Política y sociedad, núm. 30, 1999, p. 195; SÁBADA, C., «Interactividad y comunidades virtuales en el entorno de la world wide web», en Comunicación y Sociedad, núm. 1, 2010, pp. 156-157].

${ }^{9} \mathrm{Al}$ mercado electrónico se incorpora un número creciente de consumidores que pueden realizar compras de manera instantánea, sin necesidad de mantener relaciones estables con la contraparte, sin límite de horarios y sin restricciones de momento ni de lugar.

${ }^{10}$ Varias han sido las respuestas adoptadas frente a este nuevo reto: algunas empresas han optado por la sustitución del tradicional establecimiento material en el que surgieron por un modelo de negocio entera y exclusivamente virtual o telemático. Otras, en cambio, han preferido complementar ambos tipos de mercados, permaneciendo abiertas al público de un modo físico, pero sirviéndose, al mismo tiempo, de estos nuevos instrumentos para potenciar el volumen de sus ventas. Por último, se encuentran aquellas empresas que nacen unidas a esta nueva cultura (las conocidas como empresas "punto-com"). 
desarrollo de relaciones comerciales y el poder de competir en pie de igualdad con organizaciones superiores en tamaño ${ }^{11}$.

Ahora bien, como resulta lógico, nunca todo cambio es enteramente positivo. La inmaterialidad de estos procesos origina desconfianza en el consumidor, que, entre otras cosas, no puede verificar en el momento de efectuar la adquisición el estado y las características reales del producto o servicio. De la misma manera, cuestiones tales como la incertidumbre acerca de la validez y eficacia de las transacciones que se producen vía electrónica, los problemas derivados de la perfección y prueba de los contratos celebrados por este medio, la distribución de riesgos y delimitación de responsabilidades entre los distintos sujetos intervinientes o la dificultad de determinar la ley y jurisdicción aplicables en caso de litigio como consecuencia de la naturaleza transfronteriza tradicionalmente anudada a este comercio, obstaculizan, a menudo, el desarrollo integral de esta nueva modalidad virtual ${ }^{12}$.

El reto reside enencontrar soluciones adecuadas que impriman confianza suficiente (especialmente en el consumidor o usuario en cuanto parte negocial más débil) hacia este nuevo sistema. Par conseguir este objetivo se han de desarrollar, con carácter primordial, medios de solución de controversias que, alternativos a los generalmente más lentos y costosos procedimientos judiciales, permitanuna protección eficaz de las partes intervinientes. Adicionalmente, y profundizando en el protagonismo que dentro de la contratación electrónica ostenta el sector turístico, conveniente resulta también discernir cuáles de estos métodos pueden dirimir de manera solvente las disputas que se susciten como consecuencia de la adquisición de productos y la prestación de servicios de esta naturaleza.Sobre estascuestiones pivotará el presente estudio.

\section{MÉTODOS DE RESOLUCIÓN ALTERNATIVA DE DISPUTAS EN EL ÁMBITO DEL E-COMMERCE B2C: SISTEMAS ADRY ODR DE CONSUMO}

\subsection{Introducción}

En este contexto de realidad negocial virtual, numerosos son los interrogantes de carácter jurídico que han de ser resueltos. En lo que aquí respecta, conviene situar el centro de esta necesidad de certidumbre en un plano ulterior, de modo que podamos terminar respondiendo a la siguiente cuestión: ¿cuáles son los mecanismos con los que cuentan las partes para poder ver satisfechos sus derechos en caso de controversias posteriores a la celebración de un contrato constituido en el marco del comercio electrónico ${ }^{13}$

11 BOTANA GARCÍA, G. A., Comercio...cit., pp. 58, 88, 638; BRIZ ESCRIBANO, J./LASO, I., Internet y comercio electrónico: características, estrategias, desarrollo y aplicaciones, Madrid, Ed. Mundi Prensa Libros, 2013, p. 86; MOLINÍ FERNÁNDEZ, F., «Ventajas, inconvenientes e impactos territoriales del comercio electrónico», en Investigaciones geográficas, núm. 27, 2002, pp. 142-144; PAZ LLOVERAS, E., Cómo exportar, importar y hacer negocios a través de Internet, Barcelona, Ed. Gestión 2014, 1998, p. 14; SHAW, M. J./BLANNING, R./STRADER, T./WHINSTON, A., Handbook on Electronic Commerce, Berlín, Ed. Springer, 2008, pp. 19-21.

\footnotetext{
${ }^{12}$ MOLINÍ FERNÁNDEZ, F., «Ventajas...», cit., pp. 144-146.

${ }^{13}$ Sobre este tema, véase ROSSOLILLO, G., «I mezzi alternativi di risoluzione delle controversie (ADR) tra diritto comunitario e diritto internazionale», en Dir. Un. Eur., 2008, pp. 349 y ss.
} 
A fin de evitar extendernos más de lo necesario, pues ello escapa del objeto específico de este trabajo, no efectuaremos por el momento más referencia que la presente a los tradicionales remedios jurisdiccionales de solución de controversias, siempre disponibles y plenamente accesibles al amparo del artículo 24.1 de la Constitución Española de $1978^{14}$. Y ello porque, como se comprobará a lo largo de estas líneas, trataremos de focalizar nuestra atención, en un primer estadio, sobre aquellas otras vías que, alternativas de las anteriores, resultan más acordes con el nuevo modelo de negocio que se nos presenta ya como toda una realidad.

Estos métodos optativos, agrupados comúnmente bajo el acrónimo $\mathrm{ADR}^{15}$, se antojan del todo apropiados para garantizar a las partes un nivel adecuado y deseable de protección jurídica sin tener que recurrir a los lentos, caros y engorrosos procesos judiciales, harto ineficaces cuando lo que se discutenson, como suele ocurrir en muchos de estos casos, cantidades económicas poco elevadas que se suscitan en litigios que sobrepasan las fronteras de los Estados. Dentro de los mismos hemos de distinguir entre instrumentos heterónomos, en los que la solución de la controversia queda encomendada a un tercero imparcial elegido por las partes (por antonomasia y en su grado máximo, el arbitraje), e instrumentos autónomos, en los que, a diferencia de aquellos, son los mismos interesados quienes, en presencia de un tercero, resuelven sus propias disputas (como más fiel exponente, la mediación/conciliación) ${ }^{16}$. De estas tres figuras de resolución extrajudicial de conflictos, el arbitraje constituye la institución más formal y el sistema que dota a su órgano de un mayor poder de decisión ${ }^{17}$.

Esta última técnica, siguiendo a MONTERO AROCA ${ }^{18}$, puede ser definida como aquella «institución jurídica, en virtud de la cual una tercera persona, objetiva e imparcial nombrada por las partes mediando convenio o de cualquier otra forma autorizada legalmente, resuelve con base a una potestad específica el conflicto intersubjetivo de intereses jurídicos, en caso de ser la materia susceptible de libre disposición por las personas afectadas por la discrepancia». Las ventajas que trae consigo la institución arbitral en su vertiente de consumo son numerosas: en primer lugar, rapidez, ya que la resolución del conflicto se produce en un

${ }^{14}$ Este artículo reza, literalmente, como sigue: «Todas las personas tienen derecho a obtener la tutela judicial efectiva de los jueces y tribunales en el ejercicio de sus derechos e intereses legítimos, sin que, en ningún caso, pueda producirse indefensión». Tal y como estableció el Tribunal Supremo (Sala de lo ContenciosoAdministrativo) en su Sentencia número 1803/1993, de 27 de mayo, ninguno de estos sistemas (judicial y extrajudicial) primará con respecto al otro.

15 Para un estudio más pormenorizado de los métodos ADR, véase CICOGNA, M./DI RAGO, G./GIUDICE, G. N., La conciliazione commerciale, Santarcangelo di Romagna, Ed. Maggioli, 2005, pp. 40 y ss.; REVILLA GONZÁLEZ, J. A., «Los métodos alternativos de resolución de conflictos en materia de consumo: las relaciones transfronterizas», en Estudios sobre consumo, núm. 79, 2016, pp. 59 y ss.

16 GARCÍA VILlaluENGA, L./TOMILlO URBINA, J. L./VÁZQUEZ DE CASTRO, E./FERNÁNDEZ CANALES, C., Mediación, arbitraje y resolución extrajudicial de conflictos en el siglo XXI, Madrid, Ed. Reus, 2010, p. 46. Para más información acerca de los principales instrumentos extrajudiciales de resolución de disputas, véase ESTAVILLO CASTRO, F., «Medios alternativos de solución de controversias», en Jurídica Anuario del Departamento de la Universidad Iberoamericana, núm. 26, 2016, pp. 376 y ss.

${ }^{17}$ ARIAS POU, M., Manual práctico de comercio electrónico, Las Rozas (Madrid), Ed. La Ley, 2016, pp. 703-705; PAGADOR LÓPEZ, J./SERRANO CAÑAS, J. M., «Arbitraje turístico comunitariolos ODRS», en Internationaljournalofscientificmanagement and tourism, núm. 4, 2016, p. 123.

${ }^{18}$ MONTERO AROCA, J./GÓMEZ COLOMER, J. L./BARONA VILAR, S./MONTÓN REDONDO, A., Derecho jurisdiccional II. Procesal Civil, Valencia, Ed. Tirant lo Blanch, 2012, p. 884. 
plazo mucho más breve que en el sistema judicial; en segundo lugar, voluntariedad, toda vez que ambas partes se someten libremente al sistema; en tercer lugar, ejecutividad, habida cuenta de que los laudos son obligatorios; en cuarto lugar, economía, tanto de tiempo como de dinero; y, por último, unidireccionalidad, puesel proceso arbitralde consumo sólo puede comenzar si así lo insta el consumidor o usuario, nunca el empresario o profesional, más allá de que este pueda, en el íter del proceso, plantear cuestiones o pretensiones directamente vinculadas con la contienda ${ }^{19}$.

El arbitraje, a su vez, puede ser de diferentes tipos en función del criterio al que se acuda. Si atendemos a su ámbito de aplicación, podemos distinguir entre arbitrajes nacionales o internos y arbitrajes internacionales; por su objeto, encontramos arbitrajes ordinarios y arbitrajes especiales; por la forma de resolver la controversia, hay arbitrajes de derecho y arbitrajes en equidad; por el órgano encargado de decidir, el arbitraje puede ser ad hoc o institucional. Por último, en virtud del medio a través del cual puede resolverse el arbitraje, se diferencia entre arbitrajes on line y arbitrajes off line ${ }^{20}$.

Si partimos de esta última clasificación y la tomamos en consideración conjuntamente con la (r)evolución que ha supuesto el fenómeno del e-commerce, surge la posibilidad de dirimir controversias a través del empleo exclusivo de medios telemáticos. En otras palabras, como consecuencia del desarrollo de las nuevas tecnologías de la información nace, no sólo la posibilidad de celebrar contratos por medios electrónicos, sino también de poner fin por esta vía a los conflictos que surjan una vez estos perfeccionados. Aparecen en escena, de este modo, los medios extrajudiciales de solución de disputas en línea, conocidos por la expresión anglosajona Online Dispute Resolution (ODR) ${ }^{21}$.

Estos ODR presentan una tipología diversa, que varía en función de su origen. Así, podemos distinguir entre ${ }^{22}$ : de un lado, aquellos métodos extrajudiciales y electrónicos de resolución de disputas que parten de la adaptación de los ADR tradicionales (por excelencia, el e-arbitraje); de otro, aquellos que nacen de manera paralela al surgimiento del comercio electrónico (el máximo exponente de esta nueva vertiente estaría en el sistema de negociación automática, que supone una electronificación completa del proceso).

A continuación, se expone la regulación a la que se encuentran sometidos tanto los ADR como los ODR desde la perspectiva de las relaciones comerciales virtuales en las que una de las partes es un consumidor o usuario, también conocida como modalidad negocial B2C (Business toConsumer).

${ }^{19}$ VEGA VEGA, J. A., «El arbitraje en el comercio electrónico», en Anuario de la Facultad de Derecho, núm. 28, 2010, pp. 214-215.

${ }^{20}$ ARIAS POU, M., Manual...cit., pp. 715 y ss.

${ }^{21}$ En torno a los antecedentes de los ODR, véase CORTÉS, P., «Un modelo para la acreditación de los sistemas ODR en la Unión Europea», en IDP: revista de Internet, Derecho y Política, núm. 10, 2010, pp. 6 y ss.; POBLET BALCELL, M., «¿ODR 3.0?: lecciones desde Sri Lanka, la India, Kenia o Haití», en IDP: revista de Internet, Derecho y Política, núm. 10, 2010, 43 y ss. Para un estudio más profundo de estos instrumentos, véase MADRID PARRA, A., «Electronificación del arbitraje», en Riedpa: Revista Internacional de Estudios de Derecho Procesal y Arbitraje, núm. 2, 2011, pp. 23-27; RABINOVICH-EINY, O., «Mejorar la responsabilidad y el aprendizaje en la resolución de disputas a través de la tecnología», en IDP: revista de Internet, Derecho y Política, núm. 10, 2011, pp. 25 y ss.; VILALTA NICUESA, A. E., «Resolución electrónica de disputas: primeras reflexiones en torno a la necesidad de un marco normativo internacional», en IDP: revista de Internet, Derecho y Política, núm. 10, 2010, pp. 16 y ss.

${ }^{22}$ BARRAL VIÑALS, I., «La mediación...», cit., pp. 8-10. 


\subsection{Marco jurídico}

En el ámbito comunitario, la honda aspiración por facilitar la libre circulación de las personas y el correcto funcionamiento del mercado interior, ha propiciado un creciente esfuerzo institucional encaminado a garantizar un nivel adecuado de asistencia jurídica por medio del desarrollo de técnicas extrajudiciales de resolución de conflictos a lo largo y ancho del territorio de la Unión Europea, más allá de los sistemas tradicionales de superación de disputas basados en el modelo antagónico o de litigación (adversary system ${ }^{23}$. En materia de consumo, reguladora de los conflictos que puedan surgir entre un consumidor o usuario y un empresario o profesional y con el fin de procurar, en la medida de lo posible, el necesario equilibrio entre las partes, el origen más inmediato de estos mecanismos se encuentra en el Libro Verde de la Comisión, de 16 de noviembre de $1993^{24}$. Este documento tenía como finalidad diseñar un marco legal capaz de asegurar la eficacia de las normas sobre protección de los consumidores, destacando la importancia que al respecto podían cobrar estos sistemas alternativos de resolución de controversias, entre ellos, como en el caso de España, el $\operatorname{arbitraje}^{25}$.

En este estado de cosas, el 14 de febrero de 1996, la Comisión presenta una comunicación $^{26}$ apostando, de un modo claro, por los ADR en los litigios de consumo. La razón se expone de un modo claro en la primera parte de la misma, donde se advierte el problema que estos instrumentos tratan de combatir, como es la desproporción entre el volumen económico del asunto y el coste que entraña un proceso judicial. En consecuencia, se ha de perseguir por los Estados una conciliación entre la obligación de impartir justicia sin discriminaciones y las limitaciones que, en su presupuesto, padece la administración competente. Así, para conflictos (especialmente transfronterizos) de escasa cuantía (también

${ }^{23}$ RUGGERI, L., «ADR y ODR y su taxonomía: la identificación de caracteres», en IDP: revista de Internet, Derecho y Política, núm. 10, 2010, pp. 33-34.

${ }^{24}$ Libro Verde de la Comisión, de 16 de noviembre de 1993, sobre el acceso de los consumidores a la justicia y la solución de litigios relacionados con el consumo en el mercado único -COM (93) 576-. En él se planteaba el uso de sistemas alternativos de resolución de controversias en los siguientes términos: «Desde el punto de vista de los "usuarios" (tanto consumidores como empresas), el coste y la duración de un procedimiento ante los tribunales no guardan muy a menudo proporción con el valor del litigio: ello explica el desarrollo de instrumentos alternativos (y complementarios) para la solución de los litigios, junto a (previamente a) los procedimientos judiciales».

25 Interesante resulta al respecto la conclusión quinta: «Intensificación de los contactos entre los diferentes organismos de arbitraje de consumo con el fin de llevar a cabo un intercambio mutuo sobre el tema; en este marco, se recomienda investigar más a fondo el papel de determinados organismos (por ejemplo, las Cámaras de Comercio y de Industria) en la creación de regímenes de arbitraje voluntarios, de carácter sectorial o de carácter regional». En el caso español, del arbitraje como procedimiento extrajudicial se ocupa el punto II. B, pp. 34-35. Para una visión panorámica del arbitraje, véase OLIVENCIA RUIZ, M., Arbitraje: una justicia alternativa, Córdoba, Ed. Servicio de Publicaciones de la Universidad de Córdoba, pp. 7 y ss.

${ }^{26}$ Comunicación de la Comisión relativa al plan de acción sobre el acceso de los consumidores a la justicia y la solución de litigios en materia de consumo en el mercado interior, de 14 de febrero de 1996 -COM (96) 13 final-. 
conocidos como small claims $^{27}$ ), resultamuy adecuado el sistema que proponen estas técnicas alternativas, ya que su escaso coste y su gran rapidez se adecúan sobremanera a las exigencias de tales disputas, evitando que numerosos conflictos que comparten estas características queden sin resolver. En la misma línea se manifiesta la Comunicación de la Comisión de 30 de marzo de $1998^{28}$.

Surge en este mismo momento el primero de los dos textos en torno a los cuales ha estado pivotando hasta época reciente el sistema general de resolución alternativa de conflictos de consumo en el panorama comunitario. Nos estamos refiriendo a la Recomendación de la Comisión relativa a los principios aplicables a los órganos responsables de la solución extrajudicial de litigios en materia de consumo ${ }^{29}$, centrada en aquellos procedimientos susceptibles de ser resueltos mediante la intervención de un tercero que propone o impone una solución -recuérdese, métodos heterocompositivos-. Se fijan aquí los principios que han de predicarse deestos órganos, como son los de independencia, transparencia, contradicción, eficacia, legalidad, libertad y posibilidad de representación.

Junto a ella, y de manera simultánea a la Comunicación de 4 de abril de $2001^{30}$, surge la Recomendación de la Comisión 2001/310/CE ${ }^{31}$, que conforma el bloque a que hacíamos referencia en el apartado anterior. A diferencia de la Recomendación de 1998, este nuevo documento contiene principios aplicables a los órganos extrajudiciales de resolución consensual y alternativa de litigios en materia de consumo que no se hallan cubiertos por aquella, en los que se busca una aproximación de las partes a la hora de poner fin a sus controversias de mutuo acuerdo. Los principios que presiden la actuación de estos órganos son los de imparcialidad, transparencia, eficacia y equidad.

${ }^{27}$ GARCÍA MONTORO, L., «"Nuevo" modelo de resolución alternativa de conflictos de consumo a la luz del anteproyecto de ley de resolución alternativa de conflictos de consumo. Referencia a las posibilidades de supervivencia de la mediación y otros mecanismos tradicionales», en Revista CESCO de Derecho de Consumo, núm. 14, 2016, pp. 311-312; LÓPEZ SÁNCHEZ, J., «Comercio electrónico y "acceso de los consumidores a la Justicia"», en Actualidad jurídica Aranzadi, núm. 571, 2013, p. 5;

${ }^{28}$ Comunicación de la Comisión sobre la solución extrajudicial de conflictos en materia de consumo, de 30 de marzo de 1998 -COM (1998) 198 final-.

29 Recomendación 98/257/CE de la Comisión, relativa a los principios aplicables a los órganos responsables de la solución extrajudicial de los litigios en materia de consumo, de 30 de marzo de 1998 -DOCE L 115, de 17 de abril de 1998-.

${ }^{30}$ Comunicación de la Comisión relativa a la mejora del acceso de los consumidores a mecanismos alternativos de solución de litigios, de 4 de abril de 2001 -COM (2001) 161 final-. En ella se contiene, en síntesis, el mandato que están llamados a cumplir estos instrumentos alternativos: «Varios instrumentos comunitarios confieren a los consumidores una serie de derechos básicos. Ahora bien, para que estos derechos tengan valor práctico, deben existir mecanismos que permitan garantizar su ejercicio efectivo. Para que los consumidores tengan la suficiente confianza para comprar en un Estado miembro distinto del suyo y puedan beneficiarse del mercado interior, deben tener la garantía de que si no están satisfechos pueden obtener indemnización. Por otra parte, la posibilidad de recurrir a mecanismos alternativos al procedimiento judicial puede evitar litigios, puesto que incita a las partes a buscar un acuerdo antes de formalizar sus problemas con un tercero. La mera existencia, pues, de estos mecanismos puede prevenir problemas. El objetivo no es simplemente promover la confianza de los consumidores sino, a la vez, garantizar la existencia efectiva de competencia y el acceso de las empresas, especialmente las PYME, al mercado interior». En este momento, se hace de la confianza de los consumidores y del desarrollo de las nuevas tecnologías de la comunicación dos elementos indiscutibles para una futura y adecuada consolidación de los ADR.

31 Recomendación 2001/310/CE de la Comisión, relativa a los principios aplicables a los órganos extrajudiciales de resolución consensual de litigios en materia de consumo, de 4 de abril de 2001 -DOCE L 109, de 19 de abril del año 2001-. 
Ya en la actualidad, y merced a que estas dos normas no han conseguido que los mecanismos de resoluciónsupra descritos consigan establecerse de manera correcta ni funcionar satisfactoriamente en todas las áreas geográficas o sectores empresariales de la Unión $^{32}$, se ha hecho preciso dotar a las instituciones comunitarias de un nuevo marco regulador. Este viene representado por la Directiva 2013/11/CE y el Reglamento (UE) $\mathrm{n}^{\mathbf{o}}$ $524 / 2013^{33}$, que buscan homogeneizar los niveles de calidad de los procedimientos de resolución alternativa de conflictos entre todos los Estados miembros, procurando, amén de lo anterior, que estos puedan tramitar de forma eficaz los litigios que se suscitan a nivel transfronterizo ${ }^{34}$. Esta Directiva, tal y como dispone su Considerando primero, encuentra su fundamento en los artículos 169, apartados 1 y 2, letra a), del Tratado de Funcionamiento de la Unión Europea ${ }^{35}$, que establece el deber de la Unión Europea de contribuir a lograr un alto nivel de protección de los consumidores mediante las medidas que adopte en virtud del artículo 114 del mismo texto, y en el artículo 38 de la Carta de Derechos Fundamentales de la Unión Europea, que dispone que en las políticas comunitarias ha de garantizarse un nivel elevado de protección de los consumidores. Entre los principios básicos aplicables a las entidades y a los procedimientos de resolución extrajudicial de conflictos se encuentran los que a continuación se referencian: acceso a entidades y procedimientos de resolución alternativa (artículo 5); conocimientos especializados, independencia e imparcialidad (artículo 6); transparencia (artículo 7); eficacia (artículo 8); equidad (artículo 9); libertad (artículo 10) y legalidad (artículo 11). Se apuesta ya en este nuevo texto, abiertamente, por el empleo de las nuevas técnicas electrónicas para dirimir, en línea, controversias que surgen también en este medio $^{36}$.

Junto a esta Directiva se encuentra el Reglamento 524/2013, de la misma fecha ${ }^{37}$, estando interrelacionados y siendo complementarios estos dos instrumentos legislativos. Con

${ }^{32}$ Considerando quinto de la Directiva 2013/11/UE.

${ }^{33}$ Directiva 2013/11/UE del Parlamento Europeo y del Consejo, de 21 de mayo de 2013, relativa a la resolución alternativa de litigios en materia de consumo y por la que se modifica el Reglamento (CE) $\mathrm{n}^{\circ}$ 2006/2004 y la Directiva 2009/22/CE (Directiva sobre resolución alternativa de litigios en materia de consumo) DOUE L 165, de 18 de junio de 2013-.

${ }^{34}$ Para un estudio más pormenorizado, véase RALUCA STROIE, I., «Alternativas a la resolución de conflictos en materia de consumo: la Directiva 2013/11/UE del Parlamento Europeo y del Consejo y el Reglamento (UE) no 524/2013 del Parlamento Europeo y del Consejo, de 21 de mayo de 2013», en Revista CESCO de Derecho de Consumo, núm. 7, 2013, pp. 230 y ss.

35 «1. Para promover los intereses de los consumidores y garantizarles un alto nivel de protección, la Unión contribuirá a proteger la salud, la seguridad y los intereses económicos de los consumidores, así como a promover su derecho a la información, a la educación y a organizarse para salvaguardar sus intereses. 2. La Unión contribuirá a que se alcancen los objetivos a que se refiere el apartado 1 mediante: a) medidas que adopte en virtud del artículo 114 en el marco de la realización del mercado interior». Este artículo (antiguo artículo 153 TCE) ha estado vigente hasta el 1 de enero de 2013.

${ }^{36}$ Ejemplificativo resulta el Considerando décimo primero, que, por su claridad, transcribimos: «Dada la creciente importancia del comercio en línea y, en particular, del comercio transfronterizo como pilar de la actividad económica de la Unión, es necesario contar con una infraestructura para la resolución alternativa de litigios en materia de consumo que funcione correctamente y con un marco para la resolución de litigios en línea en materia de consumo derivados de transacciones en línea que esté convenientemente integrado, a fin de lograr el objetivo del Acta del Mercado Único de reforzar la confianza de los ciudadanos en el mercado interior».

${ }^{37}$ Reglamento (UE) no 524/2013 del Parlamento Europeo y del Consejo, de 21 de mayo de 2013, sobre resolución de litigios en línea en materia de consumo y por el que se modifica el Reglamento (CE) $n^{\circ}$ 2006/2004 y la Directiva 2009/22/CE -DOUE L 165, de 18 de junio de 2013-. 
idéntico fundamento, este Reglamento persigue «contribuir, a través de la consecución de un elevado nivel de protección del consumidor, al correcto funcionamiento del mercado interior, en particular en su dimensión digital, proporcionando una plataforma europea de resolución de litigios en línea que facilite la resolución extrajudicial de litigios entre consumidores y comerciantes en línea de forma independiente, imparcial, transparente, eficaz y equitativa» ${ }^{38}$. Es decir, se establece la creación de una plataforma de resolución de litigios en línea que ofrece a los consumidores y a los comerciantes una ventanilla única para la resolución extrajudicial y telemática de litigios mediante entidades de resolución alternativa que están vinculadas a esa plataforma y que ofrecen dirimir estas disputas a través de procedimientos de calidad. Por esta razón, contar con entidades como las descritas en el territorio de toda la Unión Europea constituye un requisito previo para el correcto funcionamiento de dicha plataforma ${ }^{39}$. En los artículos 5 y ss. de este Reglamento se regulan las plataformas de resolución de litigios en línea. El Centro Europeo del Consumidor, adscrito a la Agencia Española de Consumo, Seguridad Alimentaria y Nutrición (AECOSAN), es el organismo designado ante la Comisión Europea como punto de contacto de la plataforma ODR en España, proporcionando, a quien lo solicite, asistencia y apoyo en la presentación de reclamaciones a través de dicha plataforma.La plataforma consiste en un sitio web interactivo y multilingüe, que proporciona, de manera gratuita, un punto de acceso único a las personas consumidoras y a las empresas para la resolución extrajudicial de litigios contractuales derivados de contratos de compraventa o de prestación de servicios celebrados en línea (a través de Internet). El procedimiento consiste en la canalización de los litigios que se produzcan hacia los organismos de resolución de litigios. Estos organismos, han de estar conectados a la plataforma y han sido seleccionados por los Estados miembros en función de criterios de calidad, habiendo sido notificados a la Comisión Europea.

Las personas empresarias, comerciantes y las plataformas o mercados que ofrezcan sus productos o servicios de manera electrónica, tendrán la obligación de incluir en su página web un enlace, de fácil acceso, a la plataforma ODR. Si ofrecieran sus productos a través de correo electrónico, deberán incluir en éste la información sobre dicho enlace. La plataforma ODR permitirá a las personas consumidoras y comerciantes la presentación de reclamaciones cumplimentando un formulario electrónico disponible en todas las lenguas oficiales de la Unión Europea (así como en noruego e islandés), ofreciéndose la posibilidad de adjuntar los documentos oportunos.Esta plataforma ODR tendrá como punto de contacto en España el Centro Europeo del Consumidor, que remitirá de manera automática la reclamación recibida a la entidad nacional de resolución alternativa oportuna que las partes hayan acordado, estando éstas obligadas a concluir el procedimiento en un plazo de 90 días. Es de utilización sencilla y accesible, pudiéndose cumplimentar el impreso de reclamación en una serie de sencillos pasos, llevándose a cabo todo el procedimiento en línea. También es multilingüe, e incluye un servicio de traducción para la prestación de la ayuda en litigios cuando las partes estén radicadas en diferentes países europeos. Los Estados miembros designarán los organismos de resolución de litigios que se encargarán de gestionar las reclamaciones

En Derecho español, la regulación de los procedimientos extrajudiciales de resolución de conflictos de consumo encuentra su origen en el artículo 51 de la Constitución Española de

\footnotetext{
${ }^{38}$ Artículo 1 del Reglamento 524/2013.

${ }^{39}$ RALUCA STROIE, I., «Alternativas...», cit., pp. 235-238.
} 
$1978^{40}$, que sienta las bases para la defensa de los intereses de los consumidores y usuarios. Este precepto encontraría desarrollo legislativo por mor de la primigenia Ley $26 / 1984^{41}$, que, en su artículo 31, perfilaba un Sistema Arbitral de Consumo ${ }^{42}$ fundamentado en la autonomía de la voluntad de las partes ${ }^{43}$ y caracterizado por el carácter vinculante y ejecutivo del laudo.Pocos años después vio la luz la Ley 36/1988 ${ }^{44}$. Importante resulta, en lo que aquí interesa, que la Disposición Adicional Segunda de este novedoso cuerpo legal imponía al Gobierno que estableciera «reglamentariamente la denominación, composición, carácter, forma de designación y ámbito territorial de los órganos arbitrales y demás especialidades del procedimiento y del régimen jurídico del sistema arbitral que prevé, en sus características básicas, el artículo 31 de la Ley 26/1984». Consecuencia de esta imposición normativa se publicó el Real Decreto 636/1993 ${ }^{45}$, que disponía, en su primer artículo, la aplicación, con carácter supletorio, de la Ley de Arbitraje de 1988, Ley que sería, a la postre, sustituida por la hoy vigente Ley 60/2003 ${ }^{46}$. En este Real Decreto de 1993 se establece un sistema de arbitraje institucional ${ }^{47}$ caracterizado, en su procedimiento, por reunir fases consecutivas de mediación y arbitraje, aunando, por ende, procesos autocompositivos y heterocompositivos ${ }^{48}$.

Posteriormente, las Disposiciones Finales Quinta y Sexta de la Ley $44 / 2006^{49}$ impusieron un nuevo mandato al Gobierno para que, de una parte, procediera a refundir en un único texto normativo la Ley 26/1984 y las normas de transposición de las

40 «1. Los poderes públicos garantizarán la defensa de los consumidores y usuarios, protegiendo, mediante procedimientos eficaces, la seguridad, la salud y los legítimos intereses económicos de los mismos. 2. Los poderes públicos promoverán la información y la educación de los consumidores y usuarios, fomentarán sus organizaciones y oirán a éstas en las cuestiones que puedan afectar a aquéllos, en los términos que la ley establezca. 3. En el marco de lo dispuesto por los apartados anteriores, la ley regulará el comercio interior y el régimen de autorización de productos comerciales».

${ }^{41}$ Ley 26/1984, de 19 de julio, General para la Defensa de los Consumidores y Usuarios (B.O.E. núm. 176, de 24 de julio de 1984).

${ }^{42}$ Para una visión general del arbitraje de consumo, véase MARÍN LÓPEZ, M. J., «Objeto y límites del arbitraje de consumo», en Revista jurídica de Castilla-La Mancha, núm. 39, 2005, pp. 173 y ss.; ÁLVAREZ ALARCÓN, A., El sistema español de arbitraje de consumo, Madrid, Ed. Instituto Nacional de Consumo, 1999, pp. 35 y ss.

${ }^{43}$ BUJOSA VADELL, L. M., «El arbitraje de consumo», en Revista jurídica de Castilla y León, núm. 29, 2013, p. 3; LUQUIN BERGARECHE, R., «El arbitraje electrónico», en PÉREZ MORIONES, A./RIAÑO BRUN, I./MESTROT, M., El arbitraje: una nueva perspectiva desde el Derecho español y el Derecho francés, en núm. 571, 2013, pp. 117.

${ }^{44}$ Ley 36/1988, de 5 de diciembre, de Arbitraje (B.O.E. núm. 293, de 7 de diciembre de 1988).

45 Real Decreto 636/1993, de 3 de mayo, por el que se regula el Sistema Arbitral de Consumo (B.O.E. núm. 121, de 21 de mayo de 1993).

${ }^{46}$ Ley 60/2003, de 23 de diciembre, de Arbitraje (B.O.E. núm. 309, de 26 de diciembre de 2003).

${ }^{47}$ Sobre este sistema arbitral institucional, véase ISCAR DE HOYOS, J. F., «El arbitraje institucional», en Revista jurídica de Castilla y León, núm. 29, 2013, pp. 1 y ss.; MALUQUER DE MOTES I BERNET, C. J., «El arbitraje de consumo como instrumento de calidad al servicio del consumidor y del empresario», en $E l$ arbitraje de consumo: una nueva dimensión del arbitraje de derecho privado, en Arbitraje de Consumo, Valencia, Ed. Tirant lo Blanch, 2014, pp. 27 y ss.

48 BLANCO CARRASCO, M., «La alternativa de la mediación en conflictos de consumo: presente y futuro», en Anuario jurídico y económico escurialense, núm. 42, 2012, pp. 129 y ss.

${ }^{49}$ Ley 44/2006, de 29 de diciembre, de mejora de la protección de los consumidores y usuarios (B.O.E. núm. 312, de 30 de diciembre de 2006). 
Directivas comunitarias dictadas en materia de protección de consumidores y usuarios, y, de otra, para que dictase una nueva regulación del Sistema Arbitral de Consumo en sustitución de la contenida en el Real Decreto de 1993. Resultado de lo anterior surge tanto el Real Decreto Legislativo 1/2007 (en cuyos artículos 57 y 58 se recoge el Sistema Arbitral de Consumo) como el Real Decreto 231/2008 ${ }^{50}$ (modificado mediante el Real Decreto $863 / 2009^{51}$ ). Este último texto regula el conocido como sistema arbitral de consumo, que, en línea con el Real Decreto 636/1993, configura la mediación como una primera fase del proceso (artículos 37 y 38), si bien dotada de suficiente independencia conceptualy capaz de permitir que las partes alcancen un acuerdo que ponga fin al conflicto ${ }^{52}$, salvo oposición expresa de cualquiera de las mismas o cuando conste que la mediación ha sido intentada sin efecto.

Es en los artículos 57.1 TRLGDCU y 1.2 del Real Decreto de 2008 donde se contiene una definición del Sistema Arbitral de Consumo como aquel arbitraje institucional especializado, ejecutivo y vinculante, de resolución extrajudicial de conflictos surgidos entre un consumidor o usuario y un empresario o profesional que, instado a instancias de aquel, versa sobre los derechos que legal o contractualmente le corresponden.

Finalmente, al objeto de transponer la Directiva precitada, nace recientemente la Ley $7 / 2017$, de 2 de noviembre, por la que se incorpora al ordenamiento jurídico español la Directiva 2013/11/UE, del Parlamento Europeo y del Consejo, de 21 de mayo de 2013, relativa a la resolución alternativa de litigios en materia de consumo. Esta Ley tiene por finalidad (artículo 1) garantizar a los consumidores residentes en la Unión Europea el acceso a mecanismos de resolución alternativa de litigios en materia de consumo que sean de alta calidad por ser independientes, imparciales, transparentes, efectivos, rápidos y justos.A estos efectos, la presente ley tiene como objeto: determinar los requisitos que deben reunir las entidades de resolución alternativa de litigios para que, en el marco de aplicación de esta ley, puedan ser incluidas en el listado de entidades acreditadas por cada autoridad competente así como en el listado nacional de entidades que elabore la Agencia Española de Consumo, Seguridad Alimentaria y Nutrición; regular el procedimiento para la acreditación de las entidades de resolución alternativa de litigios que lo soliciten; establecer las obligaciones que deben asumir las entidades de resolución alternativa acreditadas, y garantizar el conocimiento por los consumidores de la existencia de entidades de resolución alternativa de litigios de consumo acreditadas, mediante el establecimiento de la obligación de información de los empresarios y la actuación de las Administraciones Públicas competentes.

De acuerdo con la disposición adicional segunda de esta Ley, y atendiendo a la conexión del ámbito citado con el sector turístico, para la resolución de litigios de consumo

${ }^{50}$ Real Decreto Legislativo 1/2007, de 16 de noviembre, por el que se aprueba el texto refundido de la Ley General para la Defensa de los Consumidores y Usuarios y otras leyes complementarias -TRLGDCU(B.O.E. núm. 287, de 30 de noviembre de 2007) y Real Decreto 231/2008, de 15 de febrero, por el que se regula el Sistema Arbitral de Consumo (B.O.E. núm. 48, de 25 de febrero de 2008), respectivamente. El primero de ellos reemplazó a la ya derogada Ley 26/1984, mientras que el segundo hizo lo propio con el Real Decreto 636/1993. Sobe el Real Decreto de 2008, véase MARCOS FRANCISCO, D., «El arbitraje de consumo on line en el Real Decreto 231/2008, de 15 de febrero, regulador del sistema arbitral de consumo», en Revista de la contratación electrónica, núm. 96, 2008, p. 3 y ss.

${ }^{51}$ Real Decreto 863/2009, de 14 de mayo, por el que se modifica el Real Decreto 231/2008, de 15 de febrero, por el que se regula el Sistema Arbitral de Consumo (B.O.E. núm. 126, de 25 de mayo de 2009).

\footnotetext{
${ }^{52}$ BARRAL VIÑALS, I., «La mediación...», cit., p. 5.
} 
sobre la aplicación de los Reglamentos de la Unión Europea en materia de protección de los usuarios del transporte aéreo será acreditada y notificada a la Comisión Europea una única entidad. Las entidades que den cobertura a reclamaciones de consumo de todos los sectores económicos podrán conocer igualmente de este tipo de litigios, siempre que ambas partes se hayan sometido voluntariamente a tales procedimientos. En concreto, por orden de la persona titular del Ministerio de Fomento se regulará el procedimiento de resolución alternativa de los litigios mencionados en el apartado anterior, que es de aceptación obligatoria y resultado vinculante para las compañías aéreas; hasta que entre en vigor la orden mencionada en el apartado anterior, la Agencia Estatal de Seguridad Aérea deberá acomodar su funcionamiento y procedimiento a lo previsto en esta ley con el fin de poder ser acreditada como entidad de resolución alternativa de litigios en materia de derechos de los usuarios del transporte aéreo.

\section{EL ARBITRAJE ELECTRÓNICO DE CONSUMO EN EL SECTOR TURÍSTICO}

Motor económico de nuestro país ${ }^{53}$,el sector turístico se ha convertidoen el principal generador de transacciones comerciales virtuales ${ }^{54}$. Ventajas como la posibilidad de comparar ofertas de viajes y/o estancias al instante y en cualquier momento $\mathrm{u}$ obtener reducciones de precios derivados del incremento de la competitividad entre las empresas que intervienen en el mercado motivan el éxito de esta modalidad de contratación. No obstante, inconvenientes igualmente ligados a este tipo dee-commerce(a saber, información incorrecta, inadecuación del servicio adquirido con el posteriormente prestado o incremento ulterior del precio total) determinan que el esfuerzo legislativo haya de orientarse a proporcionar una regulación encaminada a proteger de manera adecuada los intereses de los consumidores y usuarios que adquieren telemáticamente este tipo de servicios ${ }^{55}$.

Esta necesidad de protección esaún más intensa cuando surgen controversias posteriores a la perfección del acuerdo de voluntades celebrado al amparo de las nuevas tecnologías de la información y la comunicación. Disponer de un marco específico para dirimir este tipo de controversias, asegurando que este sea rápido, eficaz y dinámico, constituye un condicionante esencial para el éxito o fracaso de este concreto mercado electrónico. De ahí que el resultado de la fusión de este desarrollo tecnológico con los tradicionales medios extrajudiciales de solución de disputas constituya una opción ciertamente adecuada para interceder en los conflictos que se originan al amparo de estos contratos turísticos, generalmente de escaso coste y, por ende, ávidos de procesos eficientes y baratos.

${ }^{53}$ Según datos anuales del Instituto de Estudios Turísticos, España cerró el ejercicio 2014 recibiendo cerca de 65.000.000 de turistas internacionales, 4.300.000 más que el año anterior.

${ }^{54}$ Véase INSTITUTO NACIONAL DE ESTADÍSTICA, El comercio electrónico y el uso de las nuevas tecnologías: compras por Internet, Madrid, Catálogo de publicaciones de la Administración General del Estado, enero de 2014; ISLAS COLÍN, A./SOSA OLÁN, H., «Los deberes de información y el arbitraje on-line como mecanismos protectores del consumidor en la contratación a distancia», en Comunitaria: Revista internacional de trabajo social y ciencias sociales, núm. 13, 2017, p. 84.

55 PÉREZ MARTELL, R., «Adquisición on-line de productos turísticos y los ADR/ODR», en Los retos del Poder Judicial ante la sociedad globalizada: actas del IV Congreso Gallego de Derecho Procesal (I Internacional), A Coruña, 2 y 3 de junio de 2011, 2012, p. 1. 
Entre estos métodos heterocompositivos, como sabemos, se encuentra el arbitraje, muy conveniente por sus resoluciones vinculantes y ejecutivas para las partes. El arbitraje de consumo turístico, entendido como un arbitraje de consumo especialmente adaptado a las necesidades y demandas de los usuarios turísticos, puede erigirse en la solución ideal para mejorar la calidad de los servicios y productos ofertados. Para lograr este objetivo, se precisa la articulación e implementación de mecanismos de composición de disputas céleres, adecuados y garantistas de los derechos de quienes, necesitados normalmente de una especial protección en sus relaciones con el empresario o profesional, precisan de seguridad jurídica adicional cuando se desenvuelven, como aquí, fuera de su entorno ${ }^{56}$. Constituye, en definitiva, un instrumento útil para dirimir disputas nacidas de asuntos de pequeña cuantía que, de otra forma, no encontrarían solución alguna por el escaso equilibrio entre el coste de la reclamación y el que implica acudir a los Tribunales, ya que el desembolso económico del proceso judicial y la duración del litigio absorberían el grueso del interés de la reclamación.

Tal y como anticipamos en líneas anteriores, para la regulación del arbitraje de consumo electrónico en nuestro ordenamiento jurídico hemos de acudir, en primer lugar, a los artículos 57 y 58 TRLGDCU. Concretamente, en el apartado segundo del primero de estos preceptos se establece que el Gobierno podrá establecer reglamentariamente, entre otras cosas, «el procedimiento a través del cual se administrará el arbitraje electrónico». Sobre la base de esta previsión surgen los artículos 51 a 55 RD 231/2008 ${ }^{57}$, que, como ya dijimos, prevén la sustanciación íntegra de este proceso por medios tecnológicos, desde la solicitud de arbitraje hasta la conclusión del mismo, sin perjuicio de que alguna actuación arbitral haya de practicarse por medios tradicionales ${ }^{58}$.Por lo demás, esta peculiaridad telemática a la hora de tramitar el procedimiento arbitral no impide que este comparta las características propias de su homónimo ADR, que, por ende, pasamos a describir brevemente:

En primer lugar, en lo atinente a su estructura (artículo 4 RD 231/2008), el Sistema Arbitral de Consumo se organiza a través de las Juntas Arbitrales de Consumo, la Comisión de las Juntas Arbitrales de Consumo, el Consejo General del Sistema Arbitral de Consumo y los órganos arbitrales ${ }^{59}$. Estos últimos, ya sean unipersonales o colegiados, serán los encargados de resolver el conflicto planteado.

${ }^{56}$ BADENAS CARPIO, J. M., «El arbitraje turístico», en PETIT LAVALL, M.V. (Coord.), Lecciones de Derecho del Turismo, Valencia, Ed. Tirant lo Blanch, 2000, pp. 378; MELGOSA ARCOS, F. J., Derecho y Turismo, Salamanca, Ed. Universidad de Salamanca, 2004, p. 145.

57 Véase BARRERO RODRÍGUEZ, E., «Resolución mediante arbitraje de controversias en materia de viajes combinados: un planteamiento innecesariamente restrictivo», en AURIOLES MARTÍN, A. J. (Coord.), Aspectos jurídico-mercantiles del turismo, Madrid, Ed. Atelier, 2000, p. 67; MARTÍNEZ MARTÍNEZ, M., «Reformas en el arbitraje de consumo: Real Decreto 231/2008, de 15 de febrero, por el que se regula el Sistema Arbitral de Consumo», en Nul: estudios sobre invalidez e ineficacia, núm. 1, 2008; LABORDA VALLE, E., «El sistema arbitral de consumo», en UNED: Universidad Nacional de Educación a Distancia, 2016, p. 65.

${ }^{58} \mathrm{El}$ arbitraje de consumo se regirá, en lo no previsto en este Real Decreto, por la Ley 60/2003, cuya exposición de motivos contempla ya expresamente la posibilidad de canalizarlo vía electrónica, en los siguientes términos: «Tanto en la regulación de los requisitos de forma del convenio arbitral como en la de los del laudo la ley considera necesario admitir la utilización de cualesquiera tecnologías que cumplan los requisitos señalados. Pueden, pues, desarrollarse arbitrajes en que se utilicen tan sólo soportes informáticos, electrónicos o digitales, si las partes así lo consideran conveniente». En torno al arbitraje electrónico de consumo, véase MONTESIONOS GARCÍA, A., «El arbitraje de consumo virtual», en Consumidores y usuarios ante las nuevas tecnologías, Valencia, Tirant lo Blanch, 2008, pp. 257 y ss.

${ }^{59}$ Las Juntas Arbitrales de Consumo (artículos 5 a 8) son órganos administrativos de gestión del arbitraje institucional de consumo y que prestan servicios diversos de carácter técnico, administrativo y de secretaría, 
La competencia territorial (artículo 8 RD 231/2008) para conocer de las solicitudes individuales de arbitraje corresponderá a la Junta Arbitral de Consumo a la que ambas partes se sometan de común acuerdo. En defecto de acuerdo, recaerá en aquella en la que tenga su domicilio el consumidor (si son más de una, la de inferior ámbito territorial), salvo que exista una limitación territorial en la oferta pública de adhesión al Sistema Arbitral de Consumo (artículos 25 y ss. RD 231/2008), en cuyo caso será competente la Junta Arbitral de Consumo a la que se haya adherido la contraparte (si fueran varias, la que decida el consumidor).

La facultad de sometimiento a un arbitraje ha de realizarse por medio de un convenio arbitral (artículos 24 a 32 RD 231/2008), que podrá adoptar la forma de cláusula incorporada a un contrato o de acuerdo independiente de las partes, habiendo de expresar, en todo caso, la voluntad de las mismas de someter a la decisión de uno o más árbitros aquellas cuestiones que hayan surgido o puedan surgir en una determinada relación jurídica de consumo, contractual o no.Este convenio deberá constar por escrito (artículo 9 Ley 60/2003) y habrá de dejarse constancia documental de su existencia y aceptación. La forma del convenio arbitral no es un requisito ad solemnitatem sino ad probationem ${ }^{60}$, pudiéndose utilizar cualquier soporte tecnológico que haga posible acreditar de un modo fehaciente el consentimiento de ambas partes de dirimir el conflicto por este medio, si bien resulta recomendable la utilización de firma electrónica $^{61}$ (artículo 53 RD 231/2008) o la utilización del sistema de terceros de confianza del artículo 25 de la Ley de servicios de la sociedad de la información y de comercio electrónico ${ }^{62}$, que establece la posibilidad de las partes de pactar que un tercero archive en soporte magnético las declaraciones de voluntad que integren los contratos electrónicos y que consigne la fecha y la hora en que dichas comunicaciones se han producido $^{63}$.

El inicio del procedimiento arbitral ${ }^{64}$ tiene lugar con la solicitud presentada por el consumidor o usuario que sienta vulnerados sus derechos, bien personalmente, bien a través

tanto a las partes como a los árbitros. Por su parte, la Comisión de las Juntas Arbitrales de Consumo (artículos 9 a 11) es un órgano colegiado, adscrito funcionalmente al Instituto Nacional del Consumo a través de la Junta Arbitral Nacional, con competencia para el establecimiento de criterios homogéneos en el Sistema Arbitral de Consumo y la resolución de los recursos frente a las resoluciones de los presidentes de las Juntas Arbitrales de Consumo en determinados supuestos. El Consejo General del Sistema Arbitral de Consumo (artículos 12 a 15), siendo también un órgano colegiado adscrito funcionalmente al Instituto Nacional del Consumo, tiene encomendadas, en cambio, funciones de representación y participación en materia de arbitraje de consumo. En cuanto a los órganos arbitrales (artículos 16 a 23), la Administración, las asociaciones de consumidores y usuarios inscritas en el Registro estatal de asociaciones de consumidores y usuarios o que reúnan los requisitos exigidos por la normativa autonómica que les resulte de aplicación, las organizaciones empresariales o profesionales legalmente constituidas y, en su caso, las Cámaras de Comercio, propondrán al presidente de la Junta Arbitral de Consumo las personas que actuarán como árbitros en los procedimientos arbitrales que se sustancien en ella.

${ }^{60}$ HIERRO ANIBARRO, S., «El arbitraje especial en materia de turismo», en AURIOLES MARTÍN, A. J., Aspectos jurídico-mercantiles del turismo, Madrid, Ed. Atelier, 2003, pp. 175-180; VEGA VEGA, J. A., «El arbitraje...», cit., p. 220; GIL MEMBRADO, C., «Arbitraje turístico "on line"», en TUR FAÚNDEZ, M. N., Autorregulación y solución de conflictos en el ámbito del turismo, Madrid, Ed. COLEX, 2014, pp. 112.

${ }^{61}$ Ley 59/2003, de 19 de diciembre, de firma electrónica (B.O.E. núm. 304, de 20 de diciembre de 2003).

${ }^{62}$ Ley 34/2002, de 11 de julio, de servicios de la sociedad de la información y de comercio electrónico (B.O.E. núm. 166, de 12 de julio de 2002).

${ }^{63}$ Entre otros, el prestador de servicios de confianza "Coloriuris, S.L." (www.coloriuris.net).

${ }^{64}$ Procedimiento arbitral que se ajustará a los principios de audiencia, contradicción, igualdad entre las partes y gratuidad. Además, todos (árbitros, mediadores, partes y quienes presten servicios en las Juntas 
de sus asociaciones, ante la Junta Arbitral de Consumo que corresponda. Esta solicitud,que podrá ir acompañada de cuantas pruebas intente valerse, podrá hacerse por escrito (en cuyo caso deberá presentarse, junto con la documentación que la acompañe, por duplicado), por vía electrónica o por cualquier otro medio que permita dejar constancia de la misma y de su autenticidad. De igual modo, resulta necesario que la solicitud reúna los requisitos del artículo 34 RD 231/2008; de lo contrario, el secretario de la Junta Arbitral de Consumo requerirá al reclamante su subsanación en un plazo no superior a quince días, con la advertencia de que, de no proceder en el sentido indicado, se le tendrá por desistido y se procederá al archivo de las actuaciones ${ }^{65}$. A tales efectos, las Juntas Arbitrales de Consumo dispondrán de modelos normalizados para facilitar, al menos, la solicitud, su contestación y la aceptación del arbitraje, caso de que se trate de una empresa no adherida al Sistema Arbitral de Consumo.

Una vez determinada la competencia territorial de la Junta Arbitral de Consumo, el presidente se pronunciará sobre la admisión a trámite de la solicitud de arbitraje: si no aprecia causas de inadmisión y consta la existencia de convenio arbitral válido, acordará la iniciación del procedimiento arbitral y ordenará su notificación a las partes (el plazo de resolución será de treinta días a contar desde el siguiente a la recepción en la Junta competente de la solicitud o de su subsanación) ${ }^{66}$; si no consta la existencia de convenio arbitral previo o este no es válido, en el mismo plazo se dará traslado de la solicitud de arbitraje al reclamado indicando que ha sido admitida a trámite y dándole un plazo de quince días para la aceptación de este instrumento y de la mediación previa, si procede, así como, en su caso, para contestar a la solicitud formulando las alegaciones y presentando los documentos o proponiendo las pruebas que estime por conveniente para hacer valer sus derechos. Transcurrido el plazo, si el reclamado no contesta se ordenará el archivo de las actuaciones, notificándoselo a las partes; si contesta, se considerará iniciado el procedimiento en la fecha de entrada de la aceptación en la Junta Arbitral de Consumo, debiendo dictar su presidente, no obstante, acuerdo expreso de iniciación del procedimiento.Una vez cumplidos dichos trámites, se procederán a la designación del colegio arbitral.

Interesante resulta para nuestro estudio el artículo 40 del Real Decreto, que dispone que, en aquellos arbitrajes sectoriales que por su naturaleza requieran de una tramitación inmediata (los conflictos en el sector turístico se encuadrarían en este punto), podrá convocarse a las partes a audiencia, sin más trámite, siempre que se haya verificado la

Arbitrales de Consumo) habrán de guardar confidencialidad de la información de que conozcan en el curso de este procedimiento.

${ }^{65}$ No obstante, si faltare el requisito contemplado en el apartado f) del artículo 34 (que hace referencia a la obligación del reclamante, en el caso de que existiera oferta pública de adhesión al arbitraje en derecho, de indicar si presta su conformidad a que se resuelva de esta forma), se procederá conforme a lo dispuesto en el artículo 33.1.2 $2^{\circ}$ del mismo cuerpo legal. Este apartado dispone que «si, conforme a lo previsto en el artículo 25.1, la oferta pública de adhesión al Sistema Arbitral de Consumo se hubiera realizado al arbitraje en derecho y salvo que el consumidor o usuario haya aceptado expresamente dicho arbitraje en su solicitud, se comunicará este hecho al reclamante para que manifieste su conformidad con la decisión en derecho. En caso de no estar de acuerdo, se tratará la solicitud como si fuera dirigida a una empresa no adherida».

${ }^{66}$ En la resolución que acuerde el inicio del procedimiento arbitral constará de modo expreso la admisión de la solicitud de arbitraje, la invitación a las partes para alcanzar un acuerdo a través de la mediación previa (artículo 38 RD 231/2008) en los supuestos en que esta proceda y el traslado al reclamado de la solicitud de arbitraje para que, en el plazo de quince días, formule las alegaciones que tenga por conveniente para hacer valer su derecho y, en su caso, presente los documentos que estime pertinentes o proponga las pruebas de que intente valerse. Estas alegaciones tendrán el valor de contestación a la solicitud de arbitraje y se integrarán, junto con la solicitud y la documentación aportada por las partes, en el procedimiento arbitral. 
admisibilidad de la solicitud y la validez del convenio arbitral y se haya procedido a la designación del árbitro/s que hayan de conocer del conflicto. No obstante, cuando la Junta Arbitral de Consumo que deba conocer del arbitraje no tenga una lista de árbitros especializados acreditados ante ella, la recabará de la Junta Arbitral de Consumo de superior ámbito territorial que sí disponga de ella, a fin de designar entre los árbitros especializados acreditados incluidos en la misma a aquellos que deban conocer de la controversia.El órgano arbitral dirigirá el procedimiento, pudiendo instar a las partes a la conciliación. De todas y cada una de las alegaciones escritas, documentos y demás instrumentos que una de las partes aporte a los árbitros se dará traslado a la otra parte, quedando, de igual modo, a disposición de las partes los documentos, dictámenes periciales y demás instrumentos probatorios en los que el órgano pueda basarse para decidir.

Antes de que finalice el trámite de audiencia, las partes podrán ampliar o modificar la solicitud o la contestación, pudiendo plantearse por el reclamado una reconvención frente al reclamante, que se inadmitirá si versa sobre una materia no susceptible de arbitraje de consumo o si carece de conexión con las pretensiones de la solicitud de arbitraje, haciéndose constar en el laudo. De admitirse, se dará al reclamante reconvenido un plazo de quince días para presentar alegaciones o, en su caso, proponer prueba, retrasando, si fuera preciso, la audiencia. Esta audiencia podrá ser escrita u oral, a través de cualquier medio que permita la comunicación directa de los comparecientes, y a ella serán citadas las partes con suficiente antelación, pudiendo presentar las alegaciones y pruebas que estimen adecuadas para hacer valer sus derechos. De la audiencia se levantará acta firmada por el secretario del órgano arbitral.

Un aspecto importante dentro del proceso es el de la prueba, cuya admisión ${ }^{67}$ o rechazo será resuelto por el órgano arbitral, quien podrá proponer, si lo estima adecuado, la práctica de pruebas complementarias que considere imprescindibles para resolver la disputa. El acuerdo que adopte el órgano arbitral sobre la práctica de la prueba será notificado a las partes, indicando fecha, hora y lugar de celebración y convocatoria para la práctica de aquellas en que sea posible su presencia. Por regla general, los gastos ocasionados serán sufragados por la parte que la propusiera, las comunes o coincidentes por mitad y las de oficio por la Junta Arbitral de Consumo o por la Administración de la que dependa, en función de las disponibilidades presupuestarias ${ }^{68}$.

La decisión que decide la controversia recibe el nombre de laudo arbitral ${ }^{69}$, que tendrá lugar aun a falta de comparecencia e inactividad de las partes, siendo adoptado por mayoría en caso de que el órgano sea colegiado, con voto dirimente del presidente en ausencia de acuerdo. El plazo para dictar el laudo (salvas las excepciones del artículo 49.1. $2^{\circ}$ y $49.2 \mathrm{RD}$

${ }^{67}$ Serán admisibles como prueba los medios de reproducción de la palabra, el sonido y la imagen, así como los instrumentos que permitan archivar y conocer o reproducir palabras, datos, cifras y otras operaciones relevantes para el procedimiento. En torno a la prueba en el proceso arbitral de consumo, véase ÁLVAREZ FERNÁNDEZ, A. B., «Arbitraje de consumo: fomento de la práctica de la prueba», en Revista vasca de derecho procesal y arbitraje, núm. 3, 2009, pp. 635 y ss.

${ }^{68}$ En el arbitraje electrónico, cuando se acuerde la práctica presencial de prueba, esta se realizará por videoconferencia o por cualquier medio técnico que permita la identificación y comunicación directa de los comparecientes.

${ }^{69}$ La forma y contenido (siempre motivado) se regirá por lo dispuesto en la Ley 60/2003. Por lo demás, se dictará laudo dando por terminadas las actuaciones o sin entrar en el fondo del asunto en los supuestos del artículo 48.2 y 3 RD 231/2008. 
231/2008) será de seis meses, a contar desde el día siguiente al del inicio del procedimiento, si bien podrá ser prorrogado motivadamente por el órgano arbitral por un período no superior a dos meses, salvo acuerdo en contra de las partes.

La singularidad de la tramitación telemática del procedimiento arbitral de consumo (en este caso turístico) reside en su gestión. En concreto, en la posibilidad que tienen las Juntas Arbitrales de Consumo, en los términos que consten en sus respectivos convenios de constitución, de adscribirse voluntariamente a una administración del arbitraje sustanciado por medio de sistemas electrónicos y aplicaciones tecnológicas que habiliten tales Juntas en el ejercicio de sus competencias, sistemas y aplicaciones que deberán garantizar la compatibilidad y el intercambio de información en el seno del Sistema Arbitral de Consumo. Para ello, cabe su articulación a través de una aplicación informática centralizada que el Ministerio de Sanidad y Política Social pondrá a disposición de las Juntas Arbitrales de Consumo que voluntariamente se adscriban. La competencia se determinará atendiendo a lo dispuesto por el precitado artículo 8 del Real Decreto, mientras que la práctica de las notificaciones tendrá lugar en la sede electrónica designada por las partes, entendiéndose realizada a todos los efectos desde el día siguiente a aquel en el que conste el acceso al contenido de la actuación arbitral en cuestión ${ }^{70}$.Por último, el lugar de celebración del arbitraje electrónico será aquel en el que tenga su sede la Junta Arbitral de Consumo o la delegación territorial de la Junta Arbitral competente para conocer del procedimiento.

A nivel comunitario, se ha puesto en marcha una nueva plataforma europea de resolución de conflictos en línea. Por ello, será obligatoria la adaptación de las páginas web de comercio online para cumplir con el deber de información en los sitios web acerca de esta nueva plataforma. Los sujetos obligados a cumplir con este nuevo deber de información son las empresas establecidas en la Unión Europea que celebren contratos de compraventa o de prestación de servicios en línea (incluyendo los que ofrecen sus productos a través de correo electrónico) y los mercados en línea establecidos en la Unión. Las entidades obligadas deberán informar a los consumidores y usuarios de que la Comisión Europea facilita una plataforma online de resolución de litigios derivados de una compraventa de bienes o servicios a través de comercio electrónico ${ }^{71}$. Asimismo, estas empresas deberán facilitar a los consumidores sus direcciones de correo electrónico. La creación y desarrollo de la Plataforma de resolución de litigios en línea viene dispuesta en el Reglamento (UE) 524/2013 del Parlamento Europeo y del Consejo, siendo necesario que las partes implicadas en el conflicto se pongan de acuerdo entre sí para elegir, si así lo desean un organismo de resolución de litigios que se ocupe de su caso, existiendo en el sitio web un listado de organismos de resolución de litigios de la UE que las partes podrán seleccionar.

Teniendo en cuenta las características de las disputas que surgen en el sector turístico, las fórmulas alternativas de resolución de conflictos, y especialmente el arbitraje, dadas sus ventajas, se hacen especialmente idóneas para la resolución de las mismas.

Con respecto a los empresarios turísticos, siendo la naturaleza del arbitraje voluntaria, son necesarias las iniciativas que faciliten su adhesión al arbitraje. Esta adhesión se convierte

\footnotetext{
${ }^{70}$ No obstante, si el notificado no hubiera accedido al contenido de la actuación arbitral transcurridos diez días desde la fecha y hora de su puesta a disposición, se entenderá que la notificación se ha intentado sin efecto, habiéndose de proceder a la publicación edictal en las sedes electrónicas de las Juntas Arbitrales de Consumo adscritas al arbitraje de consumo electrónico.
}

${ }^{71}$ Esa Plataforma se encuentra disponible en el siguiente enlace: http://ec.europa.eu/consumers/odr/. 
en uno de los cometidos fundamentales que han de propiciar las Administraciones involucradas en la implantación del arbitraje. En este mismo sentido, es necesaria la aceptación del sistema por parte de las empresas turísticas, ya que prestan los servicios más elementales sobre los que se fundamenta la estancia del turista (alojamiento, alimentación, información...).

Una de las máximas prioridades de las Administraciones de consumo y turismo sería la obtención de ofertas públicas de sometimiento por parte de las empresas, pues son determinantes de la rápida resolución del conflicto a fin de asegurar el éxito del arbitraje de consumo tuitivo con el turista. Para conseguir esta adhesión es oportuno realizar campañas informativas por parte de las Administraciones (consumo-turismo), en las que se informe a los turistas de que los establecimientos adheridos prestan un servicio con un plus de calidad y garantía, de forma que se les incite a contratar con los mismos. Así, es pertinente la elaboración de avisos en los que se describan las ventajas del arbitraje y la mediación (gratuidad, rapidez...), se señale el lugar al que deben acudir para solicitar el procedimiento arbitral y se invite a los consumidores a seleccionar los establecimientos con tales características. Con estas medidas, el empresariado percibirá que los turistas conocen las implicaciones de la existencia de una oferta de adhesión y que esta es causa directa de una superior competitividad en relación con las empresas de su ramo y, por ende, un mayor volumen de beneficios.

Para persuadir al sector empresarial, hay que incentivar su adhesión al sistema también mediante otros medios: por ejemplo, el otorgamiento de premios de excelencia que puedan concederse a las empresas turísticas. Para optar a los mismos, deberá establecerse como uno de los requisitos obligatorios haber formulado una oferta pública de sometimiento al sistema de arbitraje de consumo.

En cuanto a las ventajas que obtendrían las empresas turísticas que se adhieran al arbitraje de consumo turístico tenemos, entre otras: ser incluidos en catálogos, directorios y guías de la Comunidades Autónomas en donde conste que esas empresas están adheridas al sistema arbitral con las ventajas que ello representa y beneficiarse de la publicidad institucional a favor de las empresas y profesionales adheridos al Sistema Arbitral de Consumo. Supone la ventaja de una publicidad positiva de otorgar credibilidad y calidad en su atención al cliente, favorecer el diálogo y la confianza con los turistas o evitar pleitos largos y costosos. Se precisa la colaboración entre las Administraciones autonómicas competentes en consumo y turismo y las Entidades Locales, que serás las que, en la práctica, acojan y administran el arbitraje como requisito indispensable para su eficaz funcionamiento.

Las relaciones interadministrativas con las Entidades Locales, en especial los Ayuntamientos, la labor que ejercen como Administración más próxima al consumidor, y por ende también al turista, es de todo punto esencial. Al intentar solventar los conflictos entre consumidores y empresarios, la Administración Local puede ofrecer una serie de ventajas en relación con la Autonómica o Estatal, cuyo presupuesto radica en una mayor cercanía al consumidor-turista y al establecimiento. Las instancias públicas municipales, como órganos competentes en la concesión de licencias de aperturas de establecimientos (entre ellos, los turísticos), conocen mejor las circunstancias económico-sociales de la empresa en concreto y del sector empresarial en general de la localidad. Así, constituyen un interlocutor más eficaz entre los turistas y empresarios, pues su respuesta al conflicto puede ser mucho más rápida. La certeza y rapidez de estos al admitir y discriminar los supuestos que queden al margen de 
la defensa prioritaria que se implante, abundará en la efectividad de todo el sistema en su conjunto.

Tanto por los propios rasgos que caracterizan al consumo turístico y a la posición de fragilidad del consumidor-turista como debido al deseo de especialización por parte del legislador en aras de una más satisfactoria prestación pública del arbitraje de consumo en el sector turístico, existe un fundamento que legitima la puesta en funcionamiento de sistemas de esta índole. Estos redundarán, en última instancia, en la plena satisfacción del turista que considere conculcados sus derechos y su experiencia en el destino turístico en cuestión.

Por último, las asociaciones de consumidores y de empresarios pueden ayudar a la especialización mediante la aportación de árbitros su vez expertos en el sector turístico y en la problemática usual del consumidor-turista.

\section{CONCLUSIONES}

El arbitraje puede contribuir de una manera decisiva a descongestionar una Administración de Justicia cada vez más saturada, si bien resulta preciso fortalecer y potenciar el conjunto de instrumentos que favorecen la aceptación de estas técnicas por parte de las empresas, consumidores y demás agentes económicos. Todo ello redundará, sin duda, en un mayor empleo de tales métodos y, consecuentemente, en un mayor crecimiento económico del comercio electrónico.Por lo que respecta al sector turístico, parece evidente que la solución de los conflictos que en su seno se originan por medio del empleo de la técnica extrajudicial en que elarbitraje electrónico consiste permite consolidar las buenas prácticas dentro del sector al que se dedique la empresa y la confianza del consumidor en torno a la que garantía puede suponer una resolución de conflictos ágil y rápida. Además, reduce de forma sustancial el coste de la justicia para aquellas disputas que, siendo de escasa cuantía, podrían provocar el estancamiento de la contratación on line en este sector. Parece, por tanto, adecuado dirigir el esfuerzo en torno a la difusión de este método y el desarrollo de los distintos aspectos técnicos y jurídicos que permitan una implementación efectiva y definitiva de su utilización a nivel interno e internacional.

Una verdadera consolidación del comercio electrónico en el ámbito del sector turístico pasa, irremediablemente, por alcanzar el mayor nivel de protección del consumidor o usuario, manteniendo, al mismo tiempo, un mínimo coste para las partes a la hora de ver satisfechos sus derechos con posterioridad a la perfección contractual de voluntades. Preciso resulta que este resultado se consiga mediante una protección sencilla y lo suficientemente flexible como para responder a los rápidos cambios de nuestro entorno, proporcionando, en definitiva, una seguridad jurídica tal que garantice la aplicación real y eficaz de las normas jurídicas por medio del empleo de estos instrumentos de resolución de conflictos, especialmente en el ámbito transfronterizo.

\section{BIBLIOGRAFÍA}


ÁLVAREZ ALARCÓN, A., El sistema español de arbitraje de consumo, Madrid, Ed. Instituto Nacional de Consumo, 2015, pp. 35 y ss.

ÁLVAREZ FERNÁNDEZ, A. B., «Arbitraje de consumo: fomento de la práctica de la prueba», en Revista vasca de derecho procesal y arbitraje, núm. 3, 2017, pp. 635 y ss.

AMAR RODRÍGUEZ, V. M., «La interculturalidad tecnológica: inforricos e infopobres», en Inmigración, interculturalidad y convivencia, 2002, p. 369, y «Tecnología y educación: el resurgir del cuarto mundo» en Historia Actual Online, núm. 8, 2015, p. 180.

ARIAS POU, M., Manual práctico de comercio electrónico, Las Rozas (Madrid), Ed. La Ley, 2016, pp. 703-705.

BADENAS CARPIO, J. M., «El arbitraje turístico», en PETIT LAVALL, M.V. (Coord.), Lecciones de Derecho del Turismo, Valencia, Ed. Tirant lo Blanch, 2000, pp. 375396.

BARRAL VIÑALS, I., «La mediación y el arbitraje de consumo: explorando sistemas de ODR», en IDP: revista de Internet, Derecho y Política, núm. 11, 2014, p. 5.

BARRERO RODRÍGUEZ, E., «Resolución mediante arbitraje de controversias en materia de viajes combinados: un planteamiento innecesariamente restrictivo», en AURIOLES MARTÍN, A. J. (Coord.), Aspectos jurídico-mercantiles del turismo, Madrid, Ed. Atelier, 2000, pp. 65-70.

BLANCO CARRASCO, M., «La alternativa de la mediación en conflictos de consumo: presente y futuro», en Anuario jurídico y económico escurialense, núm. 42, 2009, pp. 129 y ss.

BOTANA GARCÍA, G. A., Comercio electrónico y protección de los consumidores, Las Rozas (Madrid), Ed. La Ley, 2014, pp. 92-93, 104].

BRIZ ESCRIBANO, J./LASO, I., Internet y comercio electrónico: características, estrategias, desarrollo y aplicaciones, Madrid, Ed. Mundi Prensa Libros, 2010, p. 86.

BUJOSA VADELL, L. M., «El arbitraje de consumo», en Revista jurídica de Castilla y León, núm. 29, 2013, p. 3.

CABRERO-ALMENARA， J./AMAR RODRÍGUEZ， V. M./MONTANER， J., «Tecnologías de la información y la comunicación: más de lo mismo o más y diferente en educación», en Tavira: Revista de ciencias de la educación, núm. 24, 2017, p. 132.

CARRASCOSA LÓPEZ, V./RODRÍGUEZ DE CASTRO, E. P./POZO ARRANZ, M. A., La contratación informática: el nuevo horizonte contractual. Los contratos electrónicos e informáticos, Granada, Ed. Comares, 2017, pp. 435-436.

CICOGNA, M./DI RAGO, G./GIUDICE, G. N., La conciliazione commerciale, Santarcangelo di Romagna, Ed. Maggioli, 2015, pp. 40 y ss.

CORTÉS, P., «Un modelo para la acreditación de los sistemas ODR en la Unión Europea», en IDP: revista de Internet, Derecho y Política, núm. 10, 2010, pp. 6 y ss.

ESTAVILLO CASTRO, F., «Medios alternativos de solución de controversias», en Jurídica Anuario del Departamento de la Universidad Iberoamericana, núm. 26, 2016, pp. 376 y ss. 
FLAVIÁN BLANCO, C./GUINALÍU BLASCO, M., «La comunidad virtual: factor clave del éxito de algunos negocios en Internet», en Boletín Económico del ICE, núm. 2794, 2004, p. 24; RUBÉN BLANCO, J., «Sobre sujetos virtuales y mundos digitales: el caso de las comunidades virtuales», en Política y sociedad, núm. 30, 2008, p. 195.

GARCÍA MONTORO, L., «"Nuevo" modelo de resolución alternativa de conflictos de consumo a la luz del anteproyecto de ley de resolución alternativa de conflictos de consumo. Referencia a las posibilidades de supervivencia de la mediación y otros mecanismos tradicionales», en Revista CESCO de Derecho de Consumo, núm. 14, 2016, pp. $311-27$.

GARCÍA VILLALUENGA, L./TOMILLO URBINA, J. L./VÁZQUEZ DE CASTRO, E./FERNÁNDEZ CANALES, C., Mediación, arbitraje y resolución extrajudicial de conflictos en el siglo XXI, Madrid, Ed. Reus, 2010, p. 46.

GIL MEMBRADO, C., «Arbitraje turístico "on line"», enTUR FAÚNDEZ, M. N. (Coord.), Autorregulación y solución de conflictos en el ámbito del turismo, Madrid, Ed. COLEX, 2014, pp. 101-122.

HIERRO ANIBARRO, S., «El arbitraje especial en materia de turismo», en AURIOLES MARTÍN, A. J. (Coord.), Aspectos jurídico-mercantiles del turismo, Madrid, Ed. Atelier, 2003, pp. 173-180.

INSTITUTO NACIONAL DE ESTADÍSTICA, El comercio electrónico y el uso de las nuevas tecnologías: compras por Internet, Madrid, Catálogo de publicaciones de la Administración General del Estado, enero de 2014, pp. 45-65.

ISCAR DE HOYOS, J. F., «El arbitraje institucional», en Revista jurídica de Castilla y León, núm. 29, 2013, pp. 1 y ss.

ISLAS COLÍN, A./SOSA OLÁN, H., «Los deberes de información y el arbitraje online como mecanismos protectores del consumidor en la contratación a distancia», en Comunitaria: Revista internacional de trabajo social y ciencias sociales, núm. 13, 2017, pp. 73-100.

LABORDA VALLE, E., «El sistema arbitral de consumo», en UNED: Universidad Nacional de Educación a Distancia, 2016.

LÓPEZ SÁNCHEZ, J., «Comercio electrónico y "acceso de los consumidores a la Justicia”», en Actualidad jurídica Aranzadi, núm. 571, 2013, p. 5.

LUQUIN BERGARECHE, R., «El arbitraje electrónico», en PÉREZ MORIONES, A./RIAÑO BRUN, I./MESTROT, M., El arbitraje: una nueva perspectiva desde el Derecho español y el Derecho francés, en núm. 571, 2013, pp. 115-173.

MADRID PARRA, A., «Electronificación del arbitraje», en Riedpa: Revista Internacional de Estudios de Derecho Procesal y Arbitraje, núm. 2, 2011, pp. 23-27.

MALUQUER DE MOTES I BERNET, C. J., «El arbitraje de consumo como instrumento de calidad al servicio del consumidor y del empresario», en El arbitraje de consumo: una nueva dimensión del arbitraje de derecho privado, en Arbitraje de Consumo, Valencia, Ed. Tirant lo Blanch, 2014, pp. 27 y ss.

MARCOS FRANCISCO, D., «El arbitraje de consumo on line en el Real Decreto 231/2008, de 15 de febrero, regulador del sistema arbitral de consumo», en Revista de la contratación electrónica, núm. 96, 2008, p. 3 y ss. 
MARÍN LÓPEZ, M. J., «Objeto y límites del arbitraje de consumo», en Revista jurídica de Castilla-La Mancha, núm. 39, 2005, pp. 173 y ss.

MARTÍNEZ MARTÍNEZ, M., «Reformas en el arbitraje de consumo: Real Decreto 231/2008, de 15 de febrero, por el que se regula el Sistema Arbitral de Consumo», en Nul: estudios sobre invalidez e ineficacia, núm. 1, 2008.

MELGOSA ARCOS, F. J., Derecho y Turismo, Salamanca, Ed. Universidad de Salamanca, 2014, p. 145.

MIRANDA SERRANO, L. M./ VELA TORRES, P. J./PRÍES PICARDO, A., La contratación mercantil. Disposiciones generales. Protección de los consumidores, Madrid, Ed. Marcial Pons, 2016, p. 336.

MOLINÍ FERNÁNDEZ, F., «Ventajas, inconvenientes e impactos territoriales del comercio electrónico», en Investigaciones geográficas, núm. 27, 2012, pp. 142-144.

MONTERO AROCA, J./GÓMEZ COLOMER, J. L./BARONA VILAR, S./MONTÓN REDONDO, A., Derecho jurisdiccional II. Procesal Civil, Valencia, Ed. Tirant lo Blanch, 2002 , p. 884.

MONTESIONOS GARCÍA, A., «El arbitraje de consumo virtual», en Consumidores y usuarios ante las nuevas tecnologías, Valencia, Tirant lo Blanch, 2015, pp. 257 y ss.

PAGADOR LÓPEZ, J./SERRANO CAÑAS, J. M., «Arbitraje turístico comunitariolos ODRS», en International journalofscientificmanagement and tourism, núm. 4, 2016, pp. 117137.

PAZ LLOVERAS, E., Cómo exportar, importar y hacer negocios a través de Internet, Barcelona, Ed. Gestión 2000, 2004, p. 14.

PÉREZ LUÑO, A. E., «Internet y Derecho», en AA.VV., Informática y Derecho, Jornadas celebradas en Mérida, 1998, p. 727].

PÉREZ MARTELL, R., «Adquisición on-line de productos turísticos y los ADR/ODR», en Los retos del Poder Judicial ante la sociedad globalizada: actas del IV Congreso Gallego de Derecho Procesal (I Internacional), A Coruña, 2 y 3 de junio de 2011, 2012, p. 1.

POBLET BALCELL, M., «¿ODR 3.0?: lecciones desde Sri Lanka, la India, Kenia o Haití», en IDP: revista de Internet, Derecho y Política, núm. 10, 2010, pp. 43 y ss.

RABINOVICH-EINY, O., «Mejorar la responsabilidad y el aprendizaje en la resolución de disputas a través de la tecnología», en IDP: revista de Internet, Derecho y Política, núm. 10, 2010, pp. 25 y ss.

RALUCA STROIE, I., «Alternativas a la resolución de conflictos en materia de consumo: la Directiva 2013/11/UE del Parlamento Europeo y del Consejo y el Reglamento (UE) n 524/2013 del Parlamento Europeo y del Consejo, de 21 de mayo de 2013», en Revista CESCO de Derecho de Consumo, núm. 7, 2013, pp. 230-253.

REVILLA GONZÁLEZ, J. A., «Los métodos alternativos de resolución de conflictos en materia de consumo: las relaciones transfronterizas», en Estudios sobre consumo, núm. 79, 2006, pp. 59 y ss.

ROSSOLILLO, G., «I mezzialternativi di risoluzionedellecontroversie (ADR) tradiritto comunitario e diritto internazionale», en Dir. Un. Eur., 2012, pp. 349 y ss. 
RUBÉN BLANCO, J., «Sobre sujetos virtuales y mundos digitales: el caso de las comunidades virtuales», en Política y sociedad, núm. 30, 2007, p. 203.

RUGGERI, L., «ADR y ODR y su taxonomía: la identificación de caracteres», en IDP: revista de Internet, Derecho y Política, núm. 10, 2010, pp. 33-34.

SÁBADA, C., «Interactividad y comunidades virtuales en el entorno de la world wide web», en Comunicación y Sociedad, núm. 1, 2010, pp. 156-157].

SHAW, M. J./BLANNING, R./STRADER, T./WHINSTON, A., Handbook on Electronic Commerce, Berlín, Ed. Springer, 2011, pp. 19-21.

SUBIRANA, B./VALOR, J./CARVAJAL, P., «Entender Internet: una teoría sobre la evolución de los mercados electrónicos vía Internet», en Revista de Antiguos Alumnos del IEEM, núm. 3, 2013, p. 87.

VEGA VEGA, J. A., «El arbitraje en el comercio electrónico», en Anuario de la Facultad de Derecho, núm. 28, 2010, pp. 214-215.

VILALTA NICUESA, A. E., «Resolución electrónica de disputas: primeras reflexiones en torno a la necesidad de un marco normativo internacional», en IDP: revista de Internet, Derecho y Política, núm. 10, 2010, pp. 16 y ss. 